\title{
Limited effects of growth hormone replacement in patients with GH deficiency during long-term cure of acromegaly
}

\author{
Agatha A. van der Klaauw $\cdot$ Jeroen J. Bax $\cdot$ Ferdinand Roelfsema $\cdot$ \\ Marcel P. M. Stokkel · Gabe B. Bleeker · Nienke R. Biermasz • \\ Johannes W. A. Smit · Johannes A. Romijn · Alberto M. Pereira
}

Published online: 12 June 2009

(C) The Author(s) 2009. This article is published with open access at Springerlink.com

\begin{abstract}
The aim of this study was to assess the effects of replacement with recombinant human growth hormone (rhGH) in patients with GH deficiency (GHD) after treatment of acromegaly. Intervention study. Sixteen patients ( 8 men, age 56 years), treated for acromegaly by surgery and radiotherapy, with an insufficient GH response to insulininduced hypoglycaemia, were treated with 1 year of rhGH replacement. Study parameters were assessed at baseline and after 1 year of rhGH replacement. Study parameters were cardiac function, body composition, bone mineral density (BMD), fasting lipids, glucose, bone turnover markers, and Quality of Life (QoL). During rhGH replacement IGF-I concentrations increased from $-0.4 \pm 0.7$ to $1.0 \pm 1.5 \mathrm{SD}(P=0.001)$, with a mean daily dose of $0.2 \pm 0.1 \mathrm{mg}$ in men and $0.3 \pm 0.2 \mathrm{mg}$ in women. Nonetheless, rhGH replacement did not alter cardiac function, lipid and glucose concentrations, body composition or QoL. Bone turnover markers (PINP and $\beta$ crosslaps) levels increased $(P=0.005$ and $P=0.021$, respectively), paralleled by a small, but significant decrease in BMD of the hip. The beneficial effects of rhGH replacement in patients with GHD during cure from acromegaly are limited in this study.
\end{abstract}

A. A. van der Klaauw $(\bowtie) \cdot$ F. Roelfsema .

N. R. Biermasz - J. W. A. Smit - J. A. Romijn - A. M. Pereira Department of Endocrinology and Metabolic Diseases C4-R, Leiden University Medical Center, P.O. Box 9600, 2300 RC Leiden, The Netherlands

e-mail: a.a.van_der_klaauw@lumc.nl

J. J. Bax · G. B. Bleeker

Department of Cardiology, Leiden University Medical Center, P.O. Box 9600, 2300 RC Leiden, The Netherlands

M. P. M. Stokkel

Department of Nuclear Medicine, Leiden University Medical Center, P.O. Box 9600, 2300 RC Leiden, The Netherlands
Keywords Growth hormone deficiency Growth hormone replacement $\cdot$ Acromegaly

\section{Introduction}

Growth hormone deficiency (GHD) in adults is characterized by an adverse cardiovascular metabolic profile, altered body composition (reflected in reduced muscle strength and mass, and visceral obesity), decreased bone mass, decreased cardiac function and decreased quality of life (reviewed in [1]). Treatment with recombinant human growth hormone (rhGH) ameliorates symptoms and signs of the GHD syndrome in the short [2] and in the long-term $[3,4]$. GHD is a well-known sequel of pituitary radiotherapy, e.g. for non-functioning adenomas, adrenocorticotrope hormone- or prolactin-secreting adenomas [5]. Remarkably, GHD can also be induced by treatment of active acromegaly. We have documented a diminished GH increase to insulin-induced hypoglycemia during long-term follow-up in $36 \%$ of the patients with acromegaly after postsurgical radiotherapy [6].

Almost all randomized controlled studies on the efficacy of rhGH replacement in adult GHD have excluded patients previously treated for acromegaly. Nonetheless, two intervention studies have reported on the effects of rhGH replacement in patients with GHD after previous treatment of acromegaly. In a subanalysis of acromegalic patients with GHD extracted from the large KIMS database, 6 months of rhGH replacement had no significant beneficial effects in the acromegalic patients [7]. In addition, a recent study compared the effects of 2 years of rhGH replacement on body composition, muscle strength, bone mass and metabolic parameters between ten patients previously treated for acromegaly and ten patients treated for non-functioning 
pituitary disease [8]. At baseline, patients with acromegaly had decreased muscle endurance and increased LDL concentrations compared to the other patients, but after 2 years of rhGH replacement there were no differences between both groups [8].

The aim of this study was to evaluate 1 year of rhGH replacement on heart function, quality of life, glucose and lipid metabolism, body composition and bone mass and turnover in order to extend the exploration whether $\mathrm{GH}$ replacement is beneficial in acromegalic patients with GHD during long-term biochemical cure.

\section{Patients and methods}

\section{Patients}

We enrolled 16 acromegalic patients $(8$ men and 8 women), who developed GHD after combined pituitary surgery and radiotherapy in the study. Inclusion criteria were previous treatment for acromegaly by surgery and/or radiotherapy and an insufficient GH increase to insulininduced hypoglycemia (short-acting insulin $0.05-0.1 \mathrm{U} / \mathrm{kg}$ body weight, blood samples drawn at $0,20,30,45,60$ and $90 \mathrm{~min}$; nadir glucose levels below $2.2 \mathrm{mmol} / \mathrm{l}$ ) [9]. The increase in $\mathrm{GH}$ concentrations was considered insufficient, when the peak GH response was below $3 \mu \mathrm{g} / \mathrm{l}$ [10].

Fifteen patients had been treated with primary surgery and secondary conventional radiotherapy mean interval after radiotherapy 18 years (range 4-29 years). The other patient was diagnosed with pituitary apoplexy of a $\mathrm{GH}$ producing adenoma. Because $\mathrm{GH}$ concentrations remained elevated, he underwent surgery and subsequently developed complete anterior pituitary failure. Clinical details were published previously [11].

Additional hormone replacement therapy was kept stable for at least 3 months prior to study inclusion, and was only adjusted thereafter when necessary. The purpose, nature, and possible risks of the study were explained to all subjects and written informed consent was obtained. The study protocol was approved by the ethics committee of the Leiden University Medical Center.

Study design

Study parameters were assessed both at baseline and after 1 year of rhGH replacement. The following variables were measured: fasting concentrations of lipoproteins, glucose, and IGF-I, body composition, bone turnover markers and bone mass, echocardiography, and Quality of Life parameters.

Growth hormone vials of $1 \mathrm{ml}$ were manufactured and provided by Novo Nordisk Pharma, Denmark. Growth hormone replacement dose was started at $0.2 \mathrm{mg} /$ day and, subsequently, titrated in the first 12 weeks of the study to obtain an IGF-I concentration within the age- and genderadjusted reference range, according to Growth Hormone Research Society guidelines [10].

The mean age of the patients was 56 years (range 34-75 years). The interval between radiotherapy and the start of the study was 18 years (range 4-29 years). TSH deficiency was present in five patients, ACTH deficiency in nine patients, and LH-FSH deficiency in eight patients (see Table 1).

\section{Body composition}

Body weight and height, waist circumference, hip circumference, systolic and diastolic blood pressure (SBP and DBP, respectively) were measured. Waist-hip (WH) ratio was calculated. Body weight was measured to the nearest $0.1 \mathrm{~kg}$, and body height was measured barefoot to the nearest $0.001 \mathrm{~m}$. Lean body mass and fat mass were measured with DXA (Hologic 4500; Hologic Inc., Waltham, MA, USA).

\section{Markers for bone turnover and bone mass}

The following serum markers of bone turnover were measured: N-terminal propeptides of type I collagen (PINP), as a marker for bone synthesis, and $\beta$-crosslaps as a marker for bone resorption. Bone mineral density (BMD) was measured by DXA (Hologic 4500; Hologic Inc., Waltham, MA, USA). Sites measured were the lumbar

Table 1 Clinical characteristics of the 16 patients with growth hormone deficiency after acromegaly

\begin{tabular}{lll}
\hline Age (year) & Gender & Substitution therapy \\
\hline 65 & Male & None \\
65 & Male & None \\
59 & Male & Thyroxine, Testosterone, Hydrocortisone \\
75 & Female & Hydrocortisone \\
66 & Female & None \\
62 & Female & Hydrocortisone \\
66 & Female & Thyroxine, Estradiol, Hydrocortisone \\
40 & Female & Thyroxine, Estradiol, Hydrocortisone \\
43 & Male & Testosterone \\
56 & Male & Thyroxine, Testosterone, Hydrocortisone \\
48 & Male & Thyroxine, Testosterone, Hydrocortisone \\
51 & Female & None \\
34 & Female & Hydrocortisone \\
74 & Male & Testosterone \\
45 & Male & Testosterone \\
50 & Female & Hydrocortisone \\
\hline
\end{tabular}


spine (L1-L4) and the femoral neck (left and right). Mean BMD of the left and right femoral neck was calculated. Mean $T$ and $Z$ scores were calculated for total left and right hip using the NHANES reference values. The CV of BMD measurements was $1 \%$ and the machine was cross-calibrated at regular interval.

\section{Echocardiography}

Echocardiography was performed while the patients were in the left lateral decubitus position using a commercially available system (Vingmed Vivid-7, General ElectricVingmed, Milwaukee, WI, USA). Standard parasternal (long- and short-axis) and apical views (2-, and 4-, and long-axis) were obtained. M-mode images were obtained from the parasternal long-axis views for quantitative assessment of LV dimensions (inter-ventricular septum thickness (IVST), posterior wall thickness (PWT), LV enddiastolic diameter (LVEDD), LV end-systolic diameter (LVESD), fractional shortening (FS) and LV ejection fraction (LVEF)) [12].

The following parameters of diastolic function were obtained: diastolic transmitral peak velocities ( $E$ and $A$ wave) and the $E / A$ ratio. Quantitative diastolic data were derived from tissue Doppler imaging (TDI). For TDI analysis, the digital cine loops were analyzed using commercial software (Echopac 6.1; General Electric-Vingmed). The sample volume $\left(4 \mathrm{~mm}^{2}\right)$ was placed in the LV basal portion of the septum (using the 4-chamber views). The following parameters (mean values calculated from three consecutive heartbeats) were derived: early diastolic velocity $\left(E^{\prime}\right)$, late diastolic velocity $\left(A^{\prime}\right)$ and the $E^{\prime} / A^{\prime}$ ratio. The severity of valvular regurgitation was assessed by two independent expert readers blinded to the clinical data on a qualitative scale of trace, mild, moderate, or severe, using previously described methods $[13,14]$. Left ventricular mass (LVM) was calculated by the cube formula, and using the correction formula proposed by Devereux et al. [15]: $0.8 \times$ $\left\{1.04\left[(\text { LVEDD }+ \text { PWT }+ \text { IVST })^{3}-\right.\right.$ LVEDD $\left.\left.^{3}\right]\right\}+0.6$. The data were assessed by two independent observers, blinded for the clinical data of the patients.

\section{Quality of life}

\section{Quality of life was assessed using four different validated health-related quality of life questionnaires}

Hospital anxiety and depression scale (HADS): The HADS consists of 14 items pertaining to anxiety and depression. Each item is measured on a 4-point scale. Scores for the anxiety and depression subscale range from 0 to 21 and for the total score from 0 to 42 . A high score points to more severe anxiety and depression [16].
Multidimensional fatigue index (MFI-20): The MFI-20 contains 20 statements to assess fatigue [17]. Five different dimensions of fatigue (four items each) are calculated from these statements; (1) general fatigue; (2) physical fatigue; (3) reduced activity; (4) reduced motivation and (5) mental fatigue. Every statement is measured on a 5-point scale; scores vary from 0 to 20 . Higher scores indicate higher experienced fatigue.

Nottingham health profile (NHP): The NHP is frequently used in patients with pituitary disease to assess general well-being and QoL. The survey consists of 38 yes/ no questions, which are subdivided in 6 scales assessing impairments, i.e. pain ( 8 items), energy level (3 items), sleep (5 items), emotional reactions ( 9 items), social isolation (5 items) and disability/functioning, i.e. physical mobility (8 items) $[18,19]$. Subscale scores are calculated as a weighted mean of the associated items and are expressed as a value between 0 and 100 . The total score is the mean of the six subscales.

Quality of life-assessment of growth hormone deficiency in adults (QoL-AGDHA): This disease specific quality of life questionnaire has been developed specifically for the detection of deficits in needs achievements in areas which have shown to be commonly affected in adults with GHD [20]. The questionnaire comprises 25 items, which are summed to form a total score. Higher numerical scores (to a maximum of 25) denote poorer quality of life.

\section{Assays and dynamic tests}

Growth hormone reserve was evaluated by the insulin tolerance test in fasting conditions (short-acting insulin $0.05-0.1 \mathrm{U} / \mathrm{kg}$ body weight, blood samples drawn at 0,20 , 30, 45, 60 and $90 \mathrm{~min}$; the nadir glucose concentration should drop below $2.2 \mathrm{mmol} / \mathrm{l}$ ) [9]. The increase in $\mathrm{GH}$ concentration was considered insufficient, when the peak GH concentration was below $3 \mu \mathrm{g} / 1$ [10].

Serum IGF-I concentration was measured with the Immulite 2500 system (Diagnostic Products Corporation, Los Angeles, USA). The intra-assay variation was 5.0 and $7.5 \%$ at mean serum levels of 8 and $75 \mathrm{nmol} / 1$, respectively. IGF-I levels are expressed as standard deviation-scores (SDS), using lambda-mu-sigma (LMS) smoothed reference curves based on measurements in 906 healthy individuals [21, 22].

IGFBP-3 was measured using an immunometric technique on an IMMULITE Analyzer (Diagnostic Products Corporation, Los Angeles, USA). The lower limit of detection was $0.02 \mathrm{mg} / \mathrm{l}$ and inter-assay variation was 4.4 and $4.8 \%$ at 0.91 and $8.83 \mathrm{mg} / \mathrm{l}$. A Hitachi P800 auto analyzer (Roche, Mannheim, Germany) was used to quantify serum concentrations of glucose, total cholesterol and TG. HDL was measured with a homogenous enzymatic assay (Hitachi 911, Roche, Mannheim, Germany). LDL 
cholesterol concentrations (LDL) were calculated using the Friedewald formula. C-crosslinking terminal telopeptide of type I collagen ( $\beta$-crosslaps) and procollagen type I aminoterminal propeptide (PINP) by chemoluminescence immunoassay with the Modular Analytics E-170 system (Roche Diagnostics, Almere, The Netherlands).

\section{Statistics}

Statistical analysis was performed using SPSS for Windows, version 14.0 (SPSS Inc. Chicago, Illinois, USA). Results are scored as the mean \pm standard deviation (SD), unless specified otherwise. The data were analyzed with the paired samples Student's $t$-test. Statistical significance was set at $P<0.05$.

\section{Results}

IGF-1 and IGFBP-3 concentrations

One year of rhGH replacement increased IGF-I SD scores and IGF-BP3 levels (baseline IGF-I SD score: $-0.4 \pm 1.7$ and $1.0 \pm 1.5$ at 1 year, $P<0.001$; baseline IGFBP-3: $4.2 \pm 1.2 \mathrm{mg} / \mathrm{l}$ and $5.2 \pm 1.4 \mathrm{mg} / \mathrm{l}$ after 1 year, $P<0.001$ ).

Cardiovascular risk parameters and body composition

During rhGH replacement lipid profiles did not change. In addition, blood pressure (systolic and diastolic) and fasting glucose concentrations did not change (Table 2). Mean lean body mass increased by almost $4 \mathrm{~kg}$ and total fat mass

Table 2 Metabolic and antroprometric parameters before and after 1 year of rhGH replacement

\begin{tabular}{lccc}
\hline & \multicolumn{1}{l}{ Before } & \multicolumn{1}{l}{ After } & $P$-value \\
\hline Total cholesterol (mmol/l) & $6.0 \pm 1.0$ & $5.7 \pm 1.2$ & 0.317 \\
TG (mmol/l) & $1.8 \pm 1.0$ & $2.1 \pm 1.3$ & 0.222 \\
HDL-cholesterol (mmol/l) & $1.4 \pm 0.5$ & $1.4 \pm 0.4$ & 0.597 \\
LDL-cholesterol (mmol/l) & $4.1 \pm 0.8$ & $3.9 \pm 1.0$ & 0.250 \\
Glucose (mmol/l) & $4.6 \pm 0.6$ & $4.7 \pm 0.5$ & 0.138 \\
SBP (mm Hg) & $138 \pm 17$ & $135 \pm 10$ & 0.222 \\
DBP (mm Hg) & $87 \pm 9$ & $88 \pm 8$ & 0.924 \\
Waist circumference (cm) & $102.8 \pm 11.4$ & $103.6 \pm 12.5$ & 0.599 \\
WH ratio & $0.9 \pm 0.1$ & $0.9 \pm 0.1$ & 0.921 \\
LBM (kg) & $57.1 \pm 13.0$ & $61.7 \pm 13.4$ & 0.102 \\
Fat mass $(\mathrm{kg})$ & $34.8 \pm 16.0$ & $31.3 \pm 14.7$ & 0.367
\end{tabular}

$T G$ triglycerides; $H D L$ high-density lipoprotein; $L D L$ low-density lipoprotein; $S B P$ systolic blood pressure; $D B P$ diastolic blood pressure; WH ratio waist-to-hip ratio; $L B M$ lean body mass decreased by approximately $3 \mathrm{~kg}$, but these differences did not reach statistical significance.

Bone parameters

RhGH replacement increased plasma concentrations of bone turnover markers (PINP and $\beta$-crosslaps) in all patients (Table 3; Fig. 1). During rhGH replacement bone mass at the lumbar spine remained unchanged in all patients, but decreased significantly at the femoral neck by $4 \%$ (Table 3; Fig. 1).

Cardiac parameters and quality of life parameters

During rhGH replacement there were no significant changes in cardiac parameters or QoL parameters (Tables 4, 5).

\section{Discussion}

In this prospective study, we evaluated the effect of rhGH treatment on a range of relevant parameters in GHD patients, previously treated for acromegaly. During rhGH replacement IGF-I concentrations increased into the

Table 3 Bone markers and biochemical parameters of bone turnover before and after 1 year rhGH replacement

\begin{tabular}{lccl}
\hline & Before & After & $P$-value \\
\hline PINP (ng/ml) & $29.1 \pm 19.5$ & $44.3 \pm 33.4$ & 0.005 \\
$\beta$ crosslaps $(\mathrm{ng} / \mathrm{ml})$ & $0.2 \pm 0.1$ & $0.3 \pm 0.2$ & 0.021 \\
BMD lumbar spine $\left(\mathrm{g} / \mathrm{cm}^{2}\right)$ & $1.1 \pm 0.2$ & $1.1 \pm 0.2$ & 0.640 \\
BMD femoral neck $\left(\mathrm{g} / \mathrm{cm}^{2}\right)$ & $0.85 \pm 0.17$ & $0.81 \pm 0.15$ & $<0.001$ \\
$T$ score total hip & $-0.30 \pm 1.5$ & $-0.24 \pm 1.4$ & 0.434 \\
$Z$ score total hip & $0.26 \pm 1.6$ & $0.37 \pm 1.5$ & 0.125
\end{tabular}

PINP N-terminal propeptides of type I collagen; $B M D$ bone mineral density

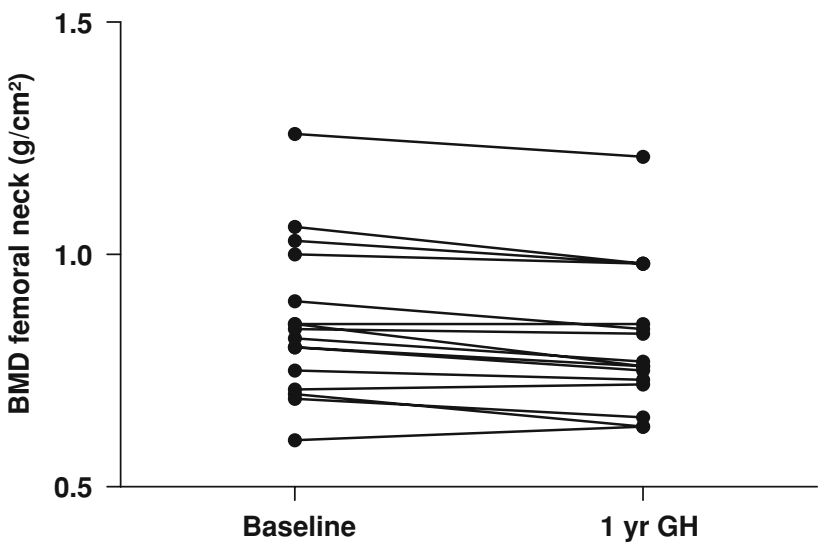

Fig. 1 Bone mineral density decreased in all patients during 1 year rhGH replacement $(n=16, P<0.001)$ 
Table 4 Cardiac parameters before and after 1 year rhGH replacement

\begin{tabular}{lccc}
\hline & Before & After & $P$-value \\
\hline LVEDD (mm) & $51.6 \pm 5.8$ & $47.0 \pm 15.5$ & 0.165 \\
LVESD (mm) & $34.3 \pm 4.4$ & $32.6 \pm 7.5$ & 0.222 \\
IVST (mm) & $12.2 \pm 3.4$ & $12.4 \pm 3.9$ & 0.704 \\
PWT (mm) & $10.2 \pm 1.6$ & $10.0 \pm 1.3$ & 0.594 \\
FS $(\%)$ & $35.1 \pm 6.7$ & $37.0 \pm 6.1$ & 0.319 \\
LVEF $(\%)$ & $63.5 \pm 8.4$ & $66.3 \pm 7.5$ & 0.244 \\
$E(\mathrm{~mm} / \mathrm{s})$ & $0.5 \pm 0.2$ & $0.5 \pm 0.1$ & 0.745 \\
$A(\mathrm{~mm} / \mathrm{s})$ & $0.6 \pm 0.2$ & $0.6 \pm 0.1$ & 0.789 \\
$E / A \mathrm{ratio}$ & $1.0 \pm 0.3$ & $0.9 \pm 0.3$ & 0.589 \\
$E^{\prime}(\mathrm{cm} / \mathrm{s})$ & $0.6 \pm 0.2$ & $0.5 \pm 0.3$ & 0.629 \\
$A^{\prime}(\mathrm{cm} / \mathrm{s})$ & $0.7 \pm 0.1$ & $0.6 \pm 0.4$ & 0.300 \\
$E^{\prime} / A^{\prime}$ ratio & $0.8 \pm 0.4$ & $0.9 \pm 0.3$ & 0.589 \\
LVM $(\mathrm{g})$ & $233 \pm 64$ & $215 \pm 105$ & 0.307 \\
\hline
\end{tabular}

$L V E D D$ left ventricular end-diastolic diameter; $L V E S D$ left ventricular end-systolic diameter; FS fractional shortening; $L V E F$ left ventricular ejection fraction; IVST inter-ventricular septum thickness; $P W T$ posterior wall thickness; $L V M$ left-ventricular mass

age- and gender-adjusted normal range, but neither cardiac parameters, nor any of the cardiovascular risk parameters or quality of life parameters changed during rhGH treatment. Bone turnover markers increased during rhGH replacement, which was associated with a decrease of bone mineral density at the femoral neck of $4 \%$, whereas the bone mass of the lumbar spine remained unchanged. These data indicate that the effects of rhGH treatment of GHD patients previously treated for acromegaly are limited.

Data on the manifestations of GHD after treatment for acromegaly are limited. Two previous studies reported several clinical manifestations in this particular patient group [7, 8]. The first study compared patients with GHD after treatment for acromegaly and Cushing's disease with patients with GHD due to other etiologies [7]. No differences in body mass index, waist-hip ratio, serum lipid concentrations, bone mineral density (at the lumbar spine and femoral neck), or IGF-I SD score were found in patients with GHD after acromegaly compared with patients with GHD due to other etiologies [7]. In the second study, muscle strength, bone mass and metabolic indices were compared between ten patients previously treated for acromegaly and ten patients treated for non-functioning pituitary disease [8]. Although there were no differences between both groups after 2 years of rhGH replacement, at baseline, patients with acromegaly had a decreased muscle endurance and increased LDL concentrations compared to the other patients, which points towards differences in their response to the treatment [8]. However, body fat decreased and lean body mass increased in that study in the patients with non-functioning pituitary disease, whereas it did not change in the same number of patients with GHD after acromegaly simultaneously studied [8], in agreement with our findings.

In adult patients with GHD, rhGH replacement increases bone mineral density [23], left ventricular mass and stroke volume [24], lean body mass [1], and quality of life [25], whereas it improves the serum lipid profile [26]. These effects are apparent within 6-12 months and are maintained during continued treatment with rhGH in the long-term [4, 24, 26-29]. However, it appears that these abnormalities associated with GHD in adults are not always reversed completely solely by rhGH replacement $[29,30]$ and that some patients might benefit more from combined treatment of rhGH with, for instance, lipid-lowering agents and bisfosfonates $[31,32]$.
Table 5 Quality of life parameters at baseline and after 1 year rhGH replacement in patients with GHD after previous treatment for acromegaly

HADS, NHP, MFI-20, QoLAGDHA higher scores: more impairment

\begin{tabular}{llccc}
\hline & & \multicolumn{1}{l}{ Before } & After & $P$-value \\
\hline QoL NHP & Energy & $55.2 \pm 38.2$ & $41.8 \pm 35.4$ & 0.125 \\
& Pain & $19.4 \pm 21.8$ & $14.1 \pm 18.8$ & 0.278 \\
& Emotional reaction & $12.0 \pm 16.4$ & $13.2 \pm 20.0$ & 0.603 \\
& Sleep & $13.6 \pm 26.9$ & $14.1 \pm 24.4$ & 0.913 \\
& Physical mobility & $20.1 \pm 20.8$ & $16.0 \pm 23.7$ & 0.258 \\
\multirow{2}{*}{ QoL MFI-20 } & Social isolation & $12.0 \pm 17.1$ & $10.6 \pm 17.1$ & 0.586 \\
& General fatigue & $15.4 \pm 4.5$ & $14.2 \pm 4.7$ & 0.154 \\
& Physical fatigue & $12.9 \pm 5.2$ & $13.2 \pm 5.2$ & 0.747 \\
& Reduction in activity & $11.4 \pm 4.9$ & $11.8 \pm 4.9$ & 0.625 \\
& Reduction in motivation & $10.8 \pm 4.4$ & $10.1 \pm 4.5$ & 0.415 \\
QoL HADS & Mental fatigue & $9.3 \pm 4.6$ & $9.8 \pm 4.3$ & 0.650 \\
& Anxiety & $4.6 \pm 2.4$ & $4.9 \pm 2.3$ & 0.453 \\
& Depression & $6.0 \pm 4.4$ & $6.1 \pm 4.3$ & 0.933 \\
QoL-AGDHA & Total score & $10.6 \pm 5.0$ & $11.0 \pm 5.3$ & 0.674 \\
& & $7.6 \pm 6.1$ & $7.7 \pm 5.9$ & 0.880 \\
\hline
\end{tabular}


In our study, parameters of both bone resorption and bone formation increased, paralleled by a net decrease in bone mineral density at the femoral neck, in agreement with the observed increase in bone turnover found during 2 years of rhGH replacement in these patients by Norrman et al. [8]. In this latter study, however, no treatment differences in the response of bone mineral density between patients previously treated for acromegaly and patients previously treated for non-functioning pituitary disease were found [8]. It is important to note, however, that there are several small differences with our study. The patients in the study of Norrman et al. were included between 1991 and 1997 . Hence, the initial dose previously applied before the consensus statement of the Growth Hormone Research Society in 1998 was first based on weight in some patients, but was subsequently gradually lowered when the weight based dose regime was abandoned. In addition, almost all patients studied (90\%) were female [8]. These differences could explain the discrepant effects of rhGH replacement found on bone mineral density between the present study and the study by Norrman et al. [8].

The decrease in BMD found in our study could point towards a different response to $\mathrm{rhGH}$ replacement in patients previously exposed to persistently increased $\mathrm{GH}$ concentrations. Alternatively, this observation may indicate that the possible beneficial effect of $\mathrm{rhGH}$ replacement on bone in these patients is insufficient to compensate the ongoing bone loss after previous $\mathrm{GH}$ excess in these specific patients. In active acromegaly, bone mineral density is increased [33] and this favorable effect seems to persist after successful biochemical cure [34]. However, in patients with biochemical cure of acromegaly, radiotherapy was an independent negative predictor of bone mineral density at the femoral neck [34]. Almost all patients in our cohort had been treated previously by radiotherapy. On the other hand, in patients with adult-onset GHD due to other etiologies, some, but not all, studies have found a decreased bone mass at the lumbar spine (reviewed in [1]). Replacement with rhGH in those patients seems to modestly increase bone mineral density after 1 year [27]. However, the lack of the increase in BMD, usually seen during rhGH replacement but absent in our specific patients, is in accordance with the only other study performed in patients with GHD after treatment of acromegaly [7]. Further longer-term studies are needed to clarify this issue.

Body composition did not change during rhGH replacement, whereas it has been consistently found to be altered by rhGH replacement in patients with GHD due to other diseases (an increase in lean body mass and a decrease in body fat [1]). However, the trends seen in our study point towards similar changes in body composition in patients previously treated for acromegaly. Interestingly, body fat decreased and lean body mass increased in the study of Norrman et al. [8] in the patients with non-functioning pituitary disease, whereas it did not change in the same number of patients with GHD after acromegaly simultaneously studied. Replacement with rhGH did not improve QoL parameters. Various aspects of QoL seem to improve slightly during rhGH replacement in adults with GHD due to other diseases [25]. Therefore, it is likely that other factors in our patients with GHD after treatment for acromegaly explain the lack of effect on QoL during rhGH replacement, such as persisting joint related complaints [35] and/or unfavorable late effects of previous radiotherapy [36].

Considering the beneficial effects of $\mathrm{rhGH}$ replacement in patients with GHD due to other causes than acromegaly, substitution in this particular subgroup is warranted. We did not find many marked beneficial effects of rhGH replacement in these patients. Higher, non-physiological, doses of rhGH could possibly result in detectable changes in the targeted parameters, as has been extensively documented in patients with GHD not pre-exposed to acromegaly. In clinical practice, however, current treatment guidelines from the Growth Hormone Research Society, advocate to titrate rhGH dose to target IGF-I concentrations within the normal age-related reference range, to ensure a therapeutic dose also in those patients with severe GHD, and avoid side effects of rhGH replacement.

In conclusion, the effects of rhGH replacement in patients with GHD after treatment for acromegaly seem to be limited. The observed effect on bone resorption and in bone mineral density might be affected by ongoing bone loss despite rhGH replacement seen in acromegaly after radiotherapy, or by the response to $\mathrm{rhGH}$ of bone after previous long-term exposure to $\mathrm{GH}$ excess. Larger longterm studies in this specific patient group are warranted to clarify the issue whether the effects of rhGH replacement in GHD might be altered by previous acromegaly. However, these patients will most probably become increasingly rare since the introduction of effective drug treatment for acromegaly.

Disclosure summary The authors have nothing to disclose.

Grants or fellowships A. A. van der Klaauw is supported by an AGIKO grant of The Netherlands Organisation for Health Research and Development (grant number: 92003423). N. R. Biermasz is supported by an AGIKO and clinical fellowship grant of The Netherlands Organization for Health Research and Development (grant numbers 92003150, 90700195). The other authors have nothing to disclose.

Open Access This article is distributed under the terms of the Creative Commons Attribution Noncommercial License which permits any noncommercial use, distribution, and reproduction in any medium, provided the original author(s) and source are credited. 


\section{References}

1. de Boer H, Blok GJ, Van der Veen EA (1995) Clinical aspects of growth hormone deficiency in adults. Endocr Rev 16:63-86. doi: 10.1210/er.16.1.63

2. Maison P, Demolis P, Young J, Schaison G, Giudicelli JF, Chanson P (2000) Vascular reactivity in acromegalic patients: preliminary evidence for regional endothelial dysfunction and increased sympathetic vasoconstriction. Clin Endocrinol (Oxf) 53:445-451. doi:10.1046/j.1365-2265.2000.01127.x

3. Chrisoulidou A, Beshyah SA, Rutherford O, Spinks TJ, Mayet J, Kyd P, Anyaoku V, Haida A, Ariff B, Murphy M, Thomas E, Robinson S, Foale R, Johnston DG (2000) Effects of 7 years of growth hormone replacement therapy in hypopituitary adults. J Clin Endocrinol Metab 85:3762-3769. doi:10.1210/jc.85.10.3762

4. Gotherstrom G, Svensson J, Koranyi J, Alpsten M, Bosaeus I, Bengtsson B, Johannsson G (2001) A prospective study of 5 years of GH replacement therapy in GH-deficient adults: sustained effects on body composition, bone mass, and metabolic indices. J Clin Endocrinol Metab 86:4657-4665. doi:10.1210/jc.86.10.4657

5. Littley MD, Shalet SM, Beardwell CG, Ahmed SR, Applegate G, Sutton ML (1989) Hypopituitarism following external radiotherapy for pituitary tumours in adults. Q J Med 70:145-160

6. Biermasz NR, van Dulken H, Roelfsema F (2000) Long-term follow-up results of postoperative radiotherapy in 36 patients with acromegaly. J Clin Endocrinol Metab 85:2476-2482. doi: 10.1210/jc.85.7.2476

7. Feldt-Rasmussen U, Abs R, Bengtsson BA, Bennmarker H, Bramnert M, Hernberg-Stahl E, Monson JP, Westberg B, Wilton P, Wuster C (2002) Growth hormone deficiency and replacement in hypopituitary patients previously treated for acromegaly or Cushing's disease. Eur J Endocrinol 146:67-74. doi:10.1530/eje. 0.1460067

8. Norrman LL, Johannsson G, Sunnerhagen KS, Svensson J (2008) Baseline characteristics and the effects of two years of growth hormone $(\mathrm{GH})$ replacement therapy in adults with GH deficiency previously treated for acromegaly. J Clin Endocrinol Metab 63: 2531-2538

9. van der Klaauw AA, Pereira AM, van Thiel SW, Smit JW, Corssmit EP, Biermasz NR, Frolich M, Iranmanesh A, Veldhuis JD, Roelfsema F, Romijn JA (2006) GH deficiency in patients irradiated for acromegaly: significance of GH stimulatory tests in relation to the $24 \mathrm{~h}$ GH secretion. Eur J Endocrinol 154:851-858. doi:10.1530/eje.1.02163

10. Consensus guidelines for the diagnosis and treatment of adults with growth hormone deficiency: summary statement of the Growth Hormone Research Society Workshop on Adult Growth Hormone Deficiency (1998). J Clin Endocrinol Metab 83:379-381

11. Roelfsema F, van den Berg G, van Dulken H, Veldhuis JD, Pincus SM (1998) Pituitary apoplexy in acromegaly, a long-term follow-up study in two patients. J Endocrinol Invest 21:298-303

12. Schiller NB, Shah PM, Crawford M, DeMaria A, Devereux R, Feigenbaum H, Gutgesell H, Reichek N, Sahn D, Schnittger I (1989) Recommendations for quantitation of the left ventricle by two-dimensional echocardiography. American society of echocardiography committee on standards, subcommittee on quantitation of two-dimensional echocardiograms. J Am Soc Echocardiogr 2:358-367

13. Perry GJ, Helmcke F, Nanda NC, Byard C, Soto B (1987) Evaluation of aortic insufficiency by Doppler color flow mapping. J Am Coll Cardiol 9:952-959

14. Thomas JD (1997) How leaky is that mitral valve? Simplified Doppler methods to measure regurgitant orifice area. Circulation 95:548-550
15. Devereux RB, Alonso DR, Lutas EM, Gottlieb GJ, Campo E, Sachs I, Reichek N (1986) Echocardiographic assessment of left ventricular hypertrophy: comparison to necropsy findings. Am J Cardiol 57:450-458. doi:10.1016/0002-9149(86)90771-X

16. Zigmond AS, Snaith RP (1983) The hospital anxiety and depression scale. Acta Psychiatr Scand 67:361-370. doi:10.1111/ j.1600-0447.1983.tb09716.x

17. Smets EM, Garssen B, Bonke B, De Haes JC (1995) The multidimensional fatigue inventory (MFI) psychometric qualities of an instrument to assess fatigue. J Psychosom Res 39:315-325. doi:10.1016/0022-3999(94)00125-O

18. Hunt SM, McEwen J (1980) The development of a subjective health indicator. Sociol Health Illn 2:231-246. doi:10.1111/14679566.ep11340686

19. Hunt SM, McKenna SP, McEwen J, Backett EM, Williams J, Papp E (1980) A quantitative approach to perceived health status: a validation study. J Epidemiol Community Health 34:281-286. doi:10.1136/jech.34.4.281

20. McKenna SP, Doward LC, Alonso J, Kohlmann T, Niero M, Prieto L, Wiren L (1999) The QoL-AGHDA: an instrument for the assessment of quality of life in adults with growth hormone deficiency. Qual Life Res 8:373-383. doi:10.1023/A:100898792 2774

21. Cole TJ (1990) The LMS method for constructing normalized growth standards. Eur J Clin Nutr 44:45-60

22. Rikken B, van Doorn J, Ringeling A, Van den Brande JL, Massa G, Wit JM (1998) Plasma levels of insulin-like growth factor (IGF)-I, IGF-II and IGF-binding protein-3 in the evaluation of childhood growth hormone deficiency. Horm Res 50:166-176. doi: $10.1159 / 000023268$

23. Gotherstrom G, Bengtsson BA, Bosaeus I, Johannsson G, Svensson J (2007) Ten-year GH replacement increases bone mineral density in hypopituitary patients with adult onset GH deficiency. Eur J Endocrinol 156:55-64. doi:10.1530/eje.1.02317

24. Maison P, Chanson P (2003) Cardiac effects of growth hormone in adults with growth hormone deficiency: a meta-analysis. Circulation 108:2648-2652. doi:10.1161/01.CIR.0000100720.01867.1D

25. Deijen JB, Arwert LI, Witlox J, Drent ML (2005) Differential effect sizes of growth hormone replacement on quality of life, well-being and health status in growth hormone deficient patients: a meta-analysis. Health Qual Life Outcomes 3:63. doi:10.1186/ 1477-7525-3-63

26. Maison P, Griffin S, Nicoue-Beglah M, Haddad N, Balkau B, Chanson $P$ (2004) Impact of growth hormone $(\mathrm{GH})$ treatment on cardiovascular risk factors in GH-deficient adults: a metaanalysis of blinded, randomized, placebo-controlled trials. J Clin Endocrinol Metab 89:2192-2199. doi:10.1210/jc.2003-030840

27. Davidson P, Milne R, Chase D, Cooper C (2004) Growth hormone replacement in adults and bone mineral density: a systematic review and meta-analysis. Clin Endocrinol (Oxf) 60:92-98. doi: 10.1111/j.1365-2265.2004.01935.x

28. Gotherstrom G, Bengtsson BA, Bosaeus I, Johannsson G, Svensson J (2007) A 10-year, prospective study of the metabolic effects of growth hormone replacement in adults. J Clin Endocrinol Metab 92:1442-1445. doi:10.1210/jc.2006-1487

29. van der Klaauw AA, Romijn JA, Biermasz NR, Smit JW, van Doorn J, Dekkers OM, Roelfsema F, Pereira AM (2006) Sustained effects of recombinant $\mathrm{GH}$ replacement after 7 years of treatment in adults with $\mathrm{GH}$ deficiency. Eur $\mathrm{J}$ Endocrinol 155:701-708. doi:10.1530/eje.1.02283

30. van der Klaauw AA, Biermasz NR, Feskens EJ, Bos MB, Smit JW, Roelfsema F, Corssmit EP, Pijl H, Romijn JA, Pereira AM (2007) The prevalence of the metabolic syndrome is increased in patients with GH deficiency, irrespective of long- 
term substitution with recombinant human GH. Eur J Endocrinol 156:455-462. doi:10.1530/EJE-06-0699

31. Monson JP, Jonsson P, Koltowska-Haggstrom M, Kourides I (2007) Growth hormone (GH) replacement decreases serum total and LDL-cholesterol in hypopituitary patients on maintenance HMG CoA reductase inhibitor (statin) therapy. Clin Endocrinol (Oxf) 67:623-628

32. Biermasz NR, Hamdy NA, Janssen YJ, Roelfsema F (2001) Additional beneficial effects of alendronate in growth hormone (GH)-deficient adults with osteoporosis receiving long-term recombinant human GH replacement therapy: a randomized controlled trial. J Clin Endocrinol Metab 86:3079-3085. doi: $10.1210 /$ jc.86.7.3079

33. Colao A, Ferone D, Marzullo P, Lombardi G (2004) Systemic complications of acromegaly: epidemiology, pathogenesis, and management. Endocr Rev 25:102-152. doi:10.1210/er.2002-0022
34. Biermasz NR, Hamdy NA, Pereira AM, Romijn JA, Roelfsema F (2005) Long-term maintenance of the anabolic effects of GH on the skeleton in successfully treated patients with acromegaly. Eur J Endocrinol 152:53-60. doi:10.1530/eje.1.01820

35. Biermasz NR, Pereira AM, Smit JW, Romijn JA, Roelfsema F (2005) Morbidity after long-term remission for acromegaly; persisting joint-related complaints cause reduced quality of life. $\mathrm{J}$ Clin Endocrinol Metab 90:2731-2739

36. van der Klaauw AA, Biermasz N, Hoftijzer HC, Pereira AM, Romijn JA (2008) Previous radiotherapy negatively influences quality of life during four years of follow-up in patients cured from acromegaly. Clin Endocrinol (Oxf) 69(1):123-128 